\title{
Depression Amongst Female Patients in a Psychiatric Hospital in Edo State, Nigeria
}

\author{
Amiegheme Felicia Ehobhayi ${ }^{1}$, Adeyemo Florence O. ${ }^{2}$, Ikhimi Esosa ${ }^{1}$ \\ ${ }^{1}$ Dept of Nursing Sciences, School of Basic Medical Sciences, University of Benin, Benin City, Nigeria \\ ${ }^{2}$ Dept of Nursing, College of Health Sciences, Ladoke Akintola University of Technology, Osogbo, Nigeria
}

Email address:

doctoradeyemo@yahoo.com (Ameigheme F. E.)

\section{To cite this article:}

Amiegheme Felicia Ehobhayi, Adeyemo Florence O., Ikhimi Esosa. Depression Amongst Female Patients in a Psychiatric Hospital in Edo State, Nigeria. International Journal of Clinical and Developmental Anatomy. Vol. 3, No. 2, 2017, pp. 5-8. doi: 10.11648/j.ijcda.20170302.11

Received: August 5, 2016; Accepted: August 13, 2016; Published: April 14, 2017

\begin{abstract}
Depressive disorders are significant public health issues. They are prevalent, disabling, and often chronic, with a high economic burden to the society. The increase in occurrences of depression is a threat to families as it leads to broken homes, broken relationships (marriages) and even loss of job which in turn affects the economy. The objective of the study is to determine the prevalence of depression among female patients in a psychiatric hospital in Benin City, Nigeria. A retrospective descriptive design was employed in this study. Past records were reviewed from between January 2013 and December 2014. Respondents' informations were used for descriptive analysis. Graphs, table and chart were then developed to explain the findings more clearly. The study showed that the depression in female patients occurred high in aged between 30-40 years, and in married women. Depression is also shown to be more prevalent amongst female patients who have had no formal education and those who are Christians. Conclusively, an increase in rate of depression was noticed hence there is need for public enlightenment on the causes of depression and how to manage it.
\end{abstract}

Keywords: Depression, Female Patients, Tertiary Hospital

\section{Introduction}

Depression is an affective or mood disorder with a retardation of mental, physical and social activities, characterized by loss of interest, lack of energy and pessimism (Melinda et al, 2016). Depression is characterized by psychomotor retardation, profound decrease in physical, social and mental activities, a feeling of uneasiness, which exceeds in duration and intensity beyond normal reaction (Koshy, 2008). It is an illness in which there are thought to be changes in the chemistry of the brain. In particular, small molecules called neurotransmitters appear to be present in a wrong proportion or amount or to function incorrectly, thus provoking a variety of distressing symptoms affecting mood, rational thinking and perception (Rahman et al., 2008). Depression is a significant contributor to the global burden of disease and affects people in all communities across the world (Araya et al, 2006). The World Mental Health Survey conducted in 17 countries found that about 1 in 20 people were reported to have an episode of depression in the previous year.

Depressive disorders often start at a young age and it's often recurring (WHO, 2012). Depression can run in families, and when it does, it generally starts between the ages of 15 and 30 (Kessler, 2005). This has made depression the leading cause of disability worldwide in terms of total years lost due to disability. The demand for curbing depression and other mental health conditions is on the rise globally. A recent World Health Assembly called on the World Health Organization and its member states to take action on this direction (WHO, 2012).

Over the years, attempts have been made to elucidate the relationship between the mind and the body especially in health and in function. The clarity of the relationship would give a clue to the source of drive for every physical activity in every individual at different times of their life. The degree of drive varies in individual from time to time and it is revealed in the mood and willingness if individuals in day to day activities. Sometimes the mood is high and activities are carried out with keen interest, but at other times the mood is low and the related activities are carried out with very low 
interest and it is called Depression (Townsend, 2006).

Women experience twice the rate of depression as men, regardless of the race or ethnic background and its first onset peaks during child bearing years (Paykel, 2009). According to Brown and Harris (2008) having no employment may dispose susceptible persons to having depression, because the state of being jobless results in a feeling of inadequacy and frustration which are common stressors implicated as factors for the development of depression. Kessler et al (2006) stated that more females are more affected than males with a ratio of $2: 1$. While persons of pyknic physique, quiet, shy, withdrawn, emotionally labile and unsecured persons are more liable to depression (kentol, 2005).

Kentol (2005) stated that treatment for depression includes the following: Antidepressant, Psychotherapy, Electroconvulsive therapy (ECT), Trans cranial Magnetic Stimulation (TMS) and Vagus Nerve Stimulation (VNS). Kessler and Walter (2005) described puberty as a major reason for increased rate of depression in girls as compared to boys. Rahman et al., 2008 stated that reproductive, genetic, or other biological factor increases the risk of depression in women. In addition, working women who are single parents suffer more stress that may trigger symptoms of depression (Pelzer, 2013). Etc.

In this paper we want to know the prevalence of depression among females in a psychiatric hospital. Depression often comes with symptoms of anxiety. These problems can become chronic or recurrent and lead to substantial impairments in an individual's ability to take care of his or her everyday responsibilities. At its worst, depression can lead to suicide. Almost 1 million lives are lost yearly due to suicide, which translates to 3000 suicide deaths every day. For every person who commits suicide, 20 or more may have attempted suicide (WHO, 2012).

World health organization (2011) also predicted that by the year 2020, depression will be a leading cause of disability globally. Despite the increasing knowledge in technology and approaches in the management of depression, the rate and severity of depression grows from day to day (Kessler and Walter, 2005). In Nigeria, depression occurs in 740 out of every 100,000 persons and $65 \%$ are women (WHO, 2011). Therefore, this study aimed to explore the descriptive information including prevalence of depression among female respondents in Psychiatric Hospital in Benin City

\section{Methodology}

RESEARCH DESIGN AND STUDY SETTING: A retrospective descriptive design was used where past records were reviewed between January 2013 and December 2014. A total of 72 cases were recorded in 2013 and 92 cases in the year 2014. Psychiatric hospital in Benin City, the capital of Edo state was established in 1964 by the government of Midwestern region. The hospital offers in and out-patient services to the mentally ill persons.

DATA AND SAMPLE SIZE: An observational check list was developed for manual collection of secondary data from the case notes and the attendance register of patients. The checklist includes: Age, sex, ethnicity, marital status, religion and educational levels of respondents.

DATA ANALYSIS: The data gathered were collated, cleaned, coded, grouped and subjected to descriptive statistics on Statistical Package for Social Sciences (SPSS) version 16.0 and presented in percentages, frequencies, means and standard deviations

PROCEDURES OF DATA ANALYSIS: The descriptive method was used which involves the use of simple percentage and graph were used to analyze the data.

ETHICAL APPROVAL: This study obtained ethical approval from the Chief Medical Director of the Psychiatric Hospital, Benin City, Nigeria. We had given more attention towards moral and ethical issues such as; confidentiality of data information of respondents during the study period.

\section{Results}

Table 1 shows the age distribution of the female patients suffering from depression in the psychiatric hospital. The mean age range falls between $30-39$ years. Those that fall within this age range represent $37 \%$ of the entire depressed females admitted in the hospital. $24 \%$ of the depressed females are less than 30 years old, $24 \%$ are between the ages of 40 to 49 years while $13 \%$ are within the age range of 50 to 59 years and only $2 \%$ are 60 years and above.

Table 2 shows the relationship between marital status and depression. Out of the 164 female depressed patients in a psychiatric hospital, $34 \%$ are single, $37 \%$ are married while $30 \%$ are separated/divorced. The marital status that is more affected by depression is the married ones.

Table 1. Age range and prevalence of depression $(n=164)$.

\begin{tabular}{lll}
\hline Age & Frequency & Percentage (\%) \\
\hline Below 30 years & 38 & 24 \\
30-39 years & 60 & 37 \\
40-49 years & 40 & 24 \\
50-59 years & 22 & 13 \\
60 years \& above & 4 & 2 \\
\hline
\end{tabular}

Table 2. Marital status and prevalence of depression.

\begin{tabular}{lll}
\hline Marital status & Frequency & Percentage (\%) \\
\hline Single & 56 & 34 \\
Married & 60 & 37 \\
Separated & 48 & 30 \\
\hline
\end{tabular}

Table 3 shows the relationship between educational level and depression. Of the 164 depressed female patients in the psychiatric hospital, those with no formal education (48\%) were more in the population, next in the list are those with BSc/HND academic qualification (34\%), $9 \%$ of the patients have M.sc while 7\% own senior school certificate and only $2 \%$ are $\mathrm{PhD}$ holders. This implies that those with no formal education are more susceptible to depression.

Table 4 shows relationship between religion and prevalence of depression amongst women the psychiatric hospital. Of the 164 female depressed patients, $78 \%$ of the 
depressed female patients claimed to be Christians, $18 \%$ are Muslims while only $4 \%$ are traditional worshippers (ATR). Majority of the depressed females in the hospital are Christians.

Table 3. Educational level and depression.

\begin{tabular}{lll}
\hline Educational level & Frequency & Percentage (\%) \\
\hline No formal education & 78 & 48 \\
Senior school Certificates & 12 & 7 \\
B.Sc/HND & 56 & 34 \\
M.Sc & 14 & 9 \\
$\mathrm{PhD}$ & 4 & 2 \\
\hline
\end{tabular}

Table 4. Religion and prevalence of depression.

\begin{tabular}{lll}
\hline Educational level & Frequency & Percentage (\%) \\
\hline Christian & 128 & 78 \\
Muslim & 30 & 18 \\
African Traditional Religion (ATR) & 6 & 4 \\
\hline
\end{tabular}

Table 5. Chi-square test of marital status and depression among female patients.

\begin{tabular}{llll}
\hline & $\mathbf{X}^{\mathbf{2}}$ Value & Df & p-value (2-sided) \\
\hline Pearson Chi-Square & 2.359 & 4 & 0.670 \\
Likelihood Ratio & 2.726 & 4 & 0.605 \\
Linear-by-Linear Association & .269 & 1 & 0.604 \\
No of Valid Cases & 82 & & \\
\hline
\end{tabular}

As presented in Table 5, the chi-square test show that there is no statistical significant association between marital status and depression among female patients, $\mathrm{P}=0.670>0.05$ at degree of freedom $(\mathrm{df})=4$ and $95 \%$ confidence level. This result implies that there is no significant relationship between marital status and the prevalence of depression among female patients in a tertiary health institution.

\section{Discussion of Findings}

This research focused on the prevalence of depression among female patients of a psychiatric hospital in Benin City. Our study revealed that the majority of the admitted patients were between the age ranges from 30 to 49 years. The findings of this study corroborate that of Eaton et. al (2007) who reported that $59 \%$ of their study fell within the ages of 30-40 years of age and Kessler et al (2006) who reported that people are most likely to suffer their first depressive episode between the ages of 30 and 40 years and that there is a smaller peak of incidence between age 50 and 60 years. Our study, however disagrees with Koshy (2008) in whose finding shows that the highest prevalence rate of lifetime depression is seen in the age group of 20 to 24 years with $62 \%$ in Northgate Psychiatric Hospital in London.

Findings further showed that the marital status that is most affected by depression are the married ones. The depressed married females are $37 \%$ of the entire depressed females which disagrees with the findings of Kestler et al (2006) who in his report stated that single mothers and divorced women are more likely to suffer depression as compared to single ladies. Silva and Kirkwood (2010) in their study at Dally psychiatric hospital stated that the highest rates of lifetime and 12-month depression are seen in divorced (48\%) and separated respondents $(27 \%)$ which also disagree with our findings.

Our result also showed that depressed females patients mostly affected are those with no formal education (48\%). This agrees with the research carried out by Bebington (2007) in Charlotte Psychiatry Hospital in Chicago, which showed that $38 \%$ of the respondents were illiterates, $32 \%$ had basic education and 30\% were highly educated with Master's honours and above.

Findings also showed that of the 164 depressed female patients attending psychiatric hospital, Benin City, 78\% claimed to be Christians, thus majority of the respondents were Christians. The only possible reason might be because majority of the people living in Benin are Christians. Townsend (2006) in his findings stated that depression had nothing to do with religion.

Finally, our result also stated that there is no relationship between marital status and the prevalence of depression because the range of depression in all marital status are marginal, although a little higher in married women but this disagrees with Silva and Kirkwood (2010), which states that the highest rates of depression are seen in divorced and separated respondents.

\section{Conclusion}

Depression is common amongst Nigerian women and significantly associated with socio-demographic factors. It was concluded that the prevalence of depression amongst female patients in this tertiary health institution was high and increased more in the year 2014 than in the previous year. This is a perceived threat to the society in line with the prediction of the world health organization that by the year 2020, depression will be the leading cause of worldwide disability.

\section{Recommendations}

Everyone should be enlightened on the causes of depression and how to manage major life challenges. The government should concentrate on alleviation of poverty, good housing and job opportunities in other to reduce stress in the environment that could lead to depression. The government should make counselors readily available to counsel disturbed individuals in the society and they should sponsor seminars and workshops to teach the health care professionals on depression.

\section{References}

[1] Asabor, P. R. (2006). Introductory Psychiatric and Mental Health (2nd Ed.). True Love Publication: Benin City.

[2] Araya, R., Flynn, T., Rojas, G., Fritsch, R., \& Simon, G. (2006). Cost-effectiveness of a primary care treatment program for depression in low-income women in Santiago, Chile. Am J Psychiatry, 163, 1379-1387. 
[3] Bebington, J. (2007). How depression differs in women from men: A comprehensive guide ( $7^{\text {th }}$ ed.). New York: McGrawHill Companies.

[4] Brown, G. W., \& Harris, T. (2008). Social theory of depression. Cambridge University Press: Cambridge.

[5] Eaton, W. W., Anthony, J. C. \& Gallo, J. (2007). Natural history of diagnostic interview schedule/DSM-IV major depression. The Baltimore Epidemiologic Catchment Area Follow up. Archives of General Psychiatry.

[6] Kentol, J. O. (2005). Depression Disorder. In Materia Medica Encyclopedia, 4, 2099-2101.

[7] Kessler, R. C., Macgonagle, K. A., \& Zhao, S. (2006). Lifetimes and twelve months prevalence of DSM III-R Psychiatry disorder in the United States: Results from National Co-morbidity Survey. Archives of General Psychiatry, 15 (2), 8-9.

[8] Kessler, R. C., \& Walters, E. E. (2005). Lifetime prevalence and age of onset distributions of DSM-IV disorder in the national co-morbidity survey replication. Archives of General Psychiatry, 62 (6), 593-602.

[9] Koshy, K. I. (2008). Abnormal Psychology (3rd Ed.). Oxford University Press: New-York City, United States of America.

[10] National Institute of Health (2006). Depression in women. Washington, D. C: Education Publications Centre.
[11] Melinda, S., Joanna, S. and Jeanne, S. (2016). Depression Symptoms and Warning Signs. Available from: http://www.helpguide.org/articles/depression/depressionsigns-and-symptoms.htm.

[12] Paykel, E. S. (2009). Depression in Women. The British Journal of Psychiatry, 18 (2), 82-88.

[13] Pelzer, I. (2013, December 16). Single mothers most at risk of poor mental health. Medical Press. Retrieved July 8, 2014, from http://medicalxpress.com/news/2013-12-mothers-poormental-health.html

[14] Rahman, E. C., Patel C. Q., Maselko T. E \& Kikwood, L. L. (2008). The easier approach to the management of depression for all health professionals (2nd Ed.). Ilorin, Kwara State: Adewumi Publisher.

[15] Silva, S. J. \& Kirkwood, B. B. (2010). Depression: The Predisposing influence of stress. Behavioural and Brain Science, 5 (1), 89-99.

[16] Townsend, M. C. (2006). Psychiatry mental health nursing (5th Ed.). Philadelphia: F. A Daris Company.

[17] World Health Organization. (2011). Guidelines for controlling and monitoring depression. Geneva, Switzerland: WHO.

[18] World Health Organization. (2012, November 16). World Suicide Prevention Day. World Health Organization. Retrieved from: http://www.who.int/mediacente/events/annual/world_suicide_ prevention_day/en/. 